\title{
La chanson de saint Alexis, a cura di Mario Eusebi
}

\section{Walter Meliga}

\section{(2) OpenEdition}

\section{Journals}

\section{Edizione digitale}

URL: https://journals.openedition.org/studifrancesi/38862

DOI: 10.4000/studifrancesi.38862

ISSN: 2421-5856

\section{Editore}

Rosenberg \& Sellier

\section{Edizione cartacea}

Data di pubblicazione: 1 décembre 2004

Paginazione: 330

ISSN: 0039-2944

\section{Notizia bibliografica digitale}

Walter Meliga, «La chanson de saint Alexis, a cura di Mario Eusebi», Studi Francesi [Online], 143 (XLVIII I

II) | 2004, online dal 30 novembre 2015, consultato il 19 mai 2021. URL: http://

journals.openedition.org/studifrancesi/38862 ; DOI: https://doi.org/10.4000/studifrancesi.38862

Questo documento è stato generato automaticamente il 19 mai 2021.

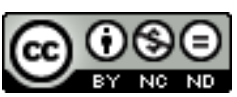

Studi Francesi è distribuita con Licenza Creative Commons Attribuzione - Non commerciale - Non opere derivate 4.0 Internazionale. 


\title{
La chanson de saint Alexis, a cura di Mario Eusebi
}

\author{
Walter Meliga
}

NOTIZIA

La chanson de saint Alexis, a cura di MARIO EUSEBI, Modena, Mucchi ("Studi, testi, manuali. Nuova serie", 2), 2001, pp. 75.

1 L'edizione è preceduta da una breve introduzione ecdotica, che chiarisce l'ipotesi ricostruttiva: il testo critico, fondato sul $\mathrm{ms}$. L (soprattutto per la forma), tende tuttavia a fornire la lezione dell'archetipo; questo, già probabilmente portatore di lezioni guaste, è stato poi sottoposto a revisioni e rimaneggiamenti. Accompagnano l'edizione un ricco e utile apparato in tre fasce (la prima dei testimoni che attestano le strofe, la seconda delle lezioni rifiutate di L, la terza delle lezioni concorrenti degli altri testimoni), la traduzione italiana e varie note di giustificazione e di commento. 